\title{
Materiais do Ministério de Educação do Brasil: das concepções de linguagem às políticas linguísticas para o ensino de surdos
}

Materials provided by Brazil's Ministry of Education: from the conceptions on language to linguistic policies for deaf education

Materiales del Ministerio de Educación de Brasil: de los conceptos de lenguaje a las políticas lingüísticas para la enseñanza de los sordos

\section{José Anchieta de Oliveira Bentes}

Professor doutor na Universidade do Estado do Pará, Belém, Pará, Brasil.

anchieta2005@yahoo.com.br

ORCID - https://orcid.org/0000-0003-1134-3677

Rita de Nazareth Souza Bentes

Professora doutora na Universidade do Estado do Pará, Belém, Pará, Brasil. ritasbentes@yahoo.com.br

ORCID - http://orcid.org/0000-0001-7565-7224

Recebido em 1 de junho de 2019

Aprovado em 6 de agosto de 2019

Publicado em 22 de outubro de 2019

\section{RESUMO}

Neste artigo, o tema em discussão é a política linguística do governo federal por meio dos materiais didático-pedagógicos direcionados à formação de professores do ensino de língua para surdos. A questão problema é: qual concepção de ensino de língua predominou como política oficial nesses materiais? O objetivo é contextualizar e analisar a política linguística proposta nesses materiais, indicando as mudanças que ocorreram, conforme os discursos constitutivos. Trata-se de uma pesquisa centrada na perspectiva dialógica da linguagem de Bakhtin e do Círculo, em especial, na concepção de linguagem de Bakhtin (2016) e Volóchinov (2017). O percurso metodológico: contextualização da política educacional da publicação dos 4 materiais didático-pedagógicos do MEC, entre 1979 e 2010; e, análise dos discursos oficiais destes a partir das categorias concepções de linguagem e política linguística. Os resultados indicam que a primeira política linguística a concepção de língua na educação especial, adotada, entre 1979 e 1995, é baseada na reabilitação da fala e da escrita; a segunda, entre 1997 e 2002, é baseada na gramática de Língua Portuguesa e da Língua Brasileira de Sinais - Libras por meio de 
http://dx.doi.org/10.5902/1984686X38402

sinais, frases e diálogos em contextos; a terceira, entre 2003 e 2010, é baseada na leitura e produção de textos em Língua Portuguesa como L2, tendo a Libras como L1; a Língua Portuguesa escrita e a Língua de Sinais estão correlacionadas no espaço de Atendimento Educacional Especializado (AEE), como política de inclusão nas redes públicas de ensino. Palavras-chave: Política linguística; Educação de surdos; Educação bilíngue.

\section{ABSTRACT}

This article discusses Brazil's federal government's linguistic policies through an analysis of the teaching materials provided for the formation of language teachers for deaf students. The research question is: what conception of language teaching predominated as an official policy throughout these materials? The objective is to describe, contextualize and analyze the linguistic policies proposed in these materials, pointing out the changes that have occurred according to their constitutive discourses. This research is centered on Bakhtin's and Bakhtin Circle's dialogical perspective of language, especially on Bakhtin's (2016) and Volóchinov's (2017) conception of language. The methodological procedures consisted of the contextualization of the educational policies applied to the editing of Brazil's Ministry of Education's four teaching materials published from 1979 to 2010 and the analysis of their official discourse based on the categorization of conceptions of language and linguistic policies. The results show that the first language policy, adopted from 1979 to 1995, based its conception of language in special education on speech and writing rehabilitation; from 1997 to 2002, the second policy based its teaching design on the grammars of Portuguese and the Língua Brasileira de Sinais (LIBRAS) through signs, sentences and dialogues in context; the third policy, implemented from 2003 to 2010, was based on the development of reading skills and production of texts in Portuguese as L2 and Libras as L1; written Portuguese language and LIBRAS are correlated in the Specialized Educational Service (SES) field as a policy of inclusion in public teaching systems.

Keywords: Linguistic policies; Deaf education; Bilingual education.

\section{RESUMEN}

En este artículo, el tema que está siendo discutido es sobre la política lingüística del gobierno federal a través de los materiales didácticos y pedagógicos dirigidos, específicamente, a la formación de profesores que enseñan lenguaje para sordos. De acuerdo con lo expuesto, el problema principal es: ¿Cuál es la concepción de la enseñanza de esta lengua que, predominaba como política oficial en estos materiales didácticos y pedagógicos? En este sentido, el objetivo de este artículo es describir, contextualizar y analizar la política lingüística propuesta en estos materiales, indicando los cambios que ocurrieron, según los discursos constitutivos. Por lo tanto, se trata de una investigación centrada en la perspectiva dialógica del lenguaje de Bakhtin y del Círculo, especialmente, en la del lenguaje de Bakhtin (2016) y Volóchinov (2017). Para el desarrollo metodológico se destacó el contexto de la política educativa de la publicación 
http://dx.doi.org/10.5902/1984686X38402

de los 4 materiales didácticos y pedagógicos del Ministerio de Educación y Cultura - MEC, entre 1979 y 2010; así como, el análisis de los discursos oficiales de los mismos a partir de las siguientes categorías: 1. concepciones del lenguaje y 2. política lingüística. Los resultados indican que la primera política lingüística de la concepción de lengua en la educación especial, adoptada entre 1979 y 1995, se fundamenta en la rehabilitación del habla y la escritura. La segunda, entre 1997 y 2002, en la gramática del portugués y en el Língua Brasileira de Sinais - Libras, mediante signos, frases y diálogos en contextos. Finalmente, la tercera, entre 2003 y 2010, se fundamenta en la lectura y producción de textos en portugués como L2, teniendo el Lenguaje de Señas de Brasil (Libras) como L1. La lengua portuguesa escrita y el Lenguaje de Señas de Brasil (Libras) están correlacionan dentro de la Atención Educacional Especializada (AEE), como política de inclusión en los sistemas escolares públicos.

Palabras clave: Política lingüística; Educación para sordos; Educación bilingüe.

\section{Introdução}

A política linguística do governo federal direcionada à orientação de professores da educação de surdos, considerando os seguintes materiais pedagógicos: i) "Proposta curricular para deficientes auditivos" (BRASIL, 1979), considerado a primeira produção oficial para a educação de surdos; ii) "Ensino de Língua Portuguesa para Surdos: caminhos para prática pedagógica" (BRASIL, 2002); iii) "Saberes e práticas da inclusão: desenvolvendo competências para 0 atendimento às necessidades educacionais especiais de alunos surdos" (BRASIL, 2003); e, iv) "Abordagem bilíngue na escolarização de pessoas com surdez" (BRASIL, 2010).

Em termos, as políticas curriculares oficiais orientaram a produção de materiais pedagógicos, e consequentemente as políticas linguísticas e as concepções de língua presentes em cada material.

Essas políticas surgiram a partir:

a) dos governos militares de Ernesto Geisel, governou de 15 de março de 1974 até 15 de março de 1979, e João Figueiredo, governou de 15 de março de 1979 até 15 de março de 1985. No ano de 1975 foram formuladas as diretrizes para a "Reformulação de Currículos para Educação Especial", as quais, na responsabilidade do Centro Nacional de Educação Especial - CENESP, sob a coordenação do Prof. José Geraldo Silveira Bueno que produziu fascículos para o atendimento da educação especial, com destaque para "Proposta curricular para deficientes auditivos" (BRASIL, 1979), com 10 volumes. 
b) do governo neoliberal ${ }^{1}$ de Fernando Henrique Cardoso (FHC), governou de $1^{\circ}$ de janeiro de 1995 até $1^{\circ}$ de janeiro de 2003. No ano 2002, foi formulado o Programa Nacional de Apoio à Educação dos Surdos e foi este programa que deu origem a produção dos dois volumes de "Ensino de Língua Portuguesa para Surdos: caminhos para a prática pedagógica" (BRASIL, 2002).

c) do governo defensor do Estado do bem-estar social representado por Luiz Inácio Lula da Silva, que governou de $1^{\circ}$ de janeiro de 2003 até $1^{\circ}$ de janeiro de 2011. Neste governo foram formulados dois Programas, o "Programa Saberes e Práticas da Inclusão" (2003) e o "Programa de Educação Inclusiva: direito à diversidade" (2007). Fruto desses programas originaram as publicações: "Saberes e práticas da inclusão" (BRASIL, 2003); e "Abordagem bilíngue na escolarização de pessoas com surdez" (BRASIL, 2010).

O Ministério da Educação e Cultura desses diversos governos orientou vários discursos sobre qual concepção de ensino de língua subsidiaria os materiais pedagógicos de formações dos professores. Esses discursos, como veremos, modificaram-se conforme os planos de governo militares, Neoliberal e Estado do bem-estar social, ora estabelecendo políticas que atendiam às exigências de órgãos e documentos internacionais que tiveram forte influência nas políticas linguísticas voltadas à educação de surdos no Brasil ou produziam posicionamentos próprios, fruto dos avanços de pesquisas realizadas nas Instituições de Ensino Superior.

Com base nesses pressupostos elaboramos a questão problema dessa pesquisa: qual concepção de ensino de língua predominou como política oficial nesses materiais de formação para professores de surdos brasileiros? Para a realização dessa pesquisa foi necessário contextualizar e analisar a política linguística do governo federal por meio dos programas educacionais especificamente pelos materiais didático-pedagógicos direcionados à formação dos professores sobre o ensino de línguas para surdos, mostrando as propostas e os discursos predominantes de política linguística que prevaleceram nesses materiais.

$\mathrm{Na}$ seção seguinte, apresentamos a discussão teórica das concepções de linguagem e a definição das políticas linguísticas do governo brasileiro; na terceira seção, é feita uma explanação sobre a abordagem teórico-metodológica com base na perspectiva dialógica da linguagem de Bakhtin (2016) e Volóchinov (2017), no Círculo Bakhtiniano; e na quarta seção, apresentamos a análise dos materiais, no que diz 
http://dx.doi.org/10.5902/1984686X38402

respeito ao posicionamento discursivo sobre a concepção de linguagem adotada oficialmente pelos governos.

\section{Concepções de linguagem}

Nesta seção, discutimos três concepções sobre a linguagem, utilizadas nessa pesquisa para a análise dos materiais pedagógicos e para definição das políticas linguísticas do Governo Federal do Brasil no período de 1979 a 2010.

A primeira tese, o subjetivismo individualista fornece uma concepção de linguagem, que se caracteriza por ser um processo criativo de criação ininterrupta, imutável, individual e estético, uma vez que o que é considerado é o fenômeno artístico, ou seja, os outros não importam.

A segunda tese, o objetivismo abstrato defende que a linguagem é uma repetição de formas linguísticas homogêneas, por meio de atos sociais, reproduzíveis a cada vez que utiliza a fala. Nos termos de Saussure: "Enquanto a linguagem é heterogênea, a língua é homogênea: constitui-se de um sistema de signos onde, de essencial, só existe a união do sentido [significado] e da imagem acústica" (SAUSSURE, 1988, p. 23).

Em acréscimo, o central desta concepção é o trabalho com formas abstratas da língua, como os fonemas, os lexemas e frase. A frase é vista como simples produto da codificação de um emissor a ser decodificado pelo leitor/ouvinte, sendo completamente explícito; o recebedor da informação - ouvinte ou leitor - são objetificados, tornados sujeitos passivos.

A terceira tese, a interação discursiva mantém a defesa de que a linguagem é um ato discursivo individual - materializa-se por enunciados concretos únicos e irrepetíveis - e completa que também é um ato social repetível, produto da ação de interlocutores em uma cadeia ininterrupta de falas. Rompe, portanto, com a formulação do enunciado como um ato monológico isolado e que, assim sendo, exige e implica a existência de autoria, interlocutores, contexto, tempo e lugar, além disso, em sua realização há pontos de vista, valorações, podendo ter tensões, contraposição de posições.

São defensores dessa tese os integrantes do chamado Círculo de Bakhtin, que conforme o Marxismo e Filosofia da Linguagem: 
http://dx.doi.org/10.5902/1984686X38402

Em sua essência, a palavra é um ato bilateral. Ela é determinada tanto por aquele de quem ela procede quanto por aquele para quem se dirige. Enquanto palavra, ela é justamente o produto das inter-relações do falante com o ouvinte. Toda palavra serve de expressão ao "um" em relação ao "outro". Na palavra, eu dou forma a mim mesmo do ponto de vista do outro e, por fim, da perspectiva da minha coletividade. A palavra é uma ponte que liga 0 eu ao outro. Ela apoia uma das extremidades em mim e a outra no interlocutor. A palavra é o território comum entre o falante e o interlocutor (VOLÓCHINOV, 2017, p. 205, ênfase do autor).

Essas três teses, como afirmamos, influenciam a definição das três concepções de linguagem aqui utilizadas. O subjetivismo individualista subsidia a formulação da concepção da linguagem como "representação do pensamento"; o objetivismo abstrato subsidia a concepção de "instrumento de comunicação"; e a terceira - a interação discursiva - subsidia a linguagem como "lugar de interação".

\section{A análise dialógica do discurso}

O referencial teórico-metodológico desta pesquisa é baseado na perspectiva dialógica da linguagem de Bakhtin e do Círculo, em especial, na concepção de linguagem (BAKHTIN, 2016) e nas tendências do pensamento filosófico-linguístico - subjetivismo individualista e objetivismo abstrato - e de interação discursiva (VOLÓCHINOV, 2017) para estabelecer as três concepções de linguagem: expressão do pensamento, instrumento de comunicação e lugar de interação.

O percurso de análise é a partir das concepções de linguagem e política linguística verificadas nos materiais, e essas categorias se constituíram: a) na identificação do conceito de língua ou de linguagem, na referência à variação linguística, na relação entre o oral e o escrito ou entre a Libras e a Língua Portuguesa escrita, b) nas considerações sobre o uso de textos e de contextos/situações, c) na relação entre sujeito e interlocutor e nas políticas linguísticas.

A contextualização e análise são feitas é a partir dos quatros (4) materiais didáticopedagógicos para identificar a concepção de linguagem proposta como política linguística, para verificar quais discursos prevaleceram nessas materialidades linguístico-discursivas que se configuraram em propostas de ensino de língua como ações dessa política.

A escolha dos quatro (4) materiais publicados se deu em função de estes serem representativos da política social e educacional, especificamente da política linguística dos três governos federais do período entre 1979 e 2010. 
http://dx.doi.org/10.5902/1984686X38402

É propósito investigar esses manuais como enunciados, para além de um simples purismo linguístico, mas buscando, sobretudo, as relações com as quais os autores e pesquisadores dialogam para a produção de textos em esferas reais. Brait (2006), uma das estudiosas da teoria do Círculo de Bakhtin, contribui para o entendimento da ADD da seguinte forma:

[...] a indissolúvel relação existente entre língua, linguagens, história e sujeitos que instaura os estudos da linguagem como lugares de produção de conhecimento de forma comprometida, responsável, e não apenas como procedimento submetido a "teorias e metodologias dominantes em determinadas épocas". Esse embasamento constitutivo diz respeito a uma concepção de linguagem, de construção e produção de sentidos necessariamente apoiadas nas relações discursivas empreendidas por sujeitos historicamente situados (BRAIT, 2006, p. 10).

Nesse posicionamento a autora traz a concepção dos estudos do círculo bakhtiniano, com o que denomina de Análise Dialógica do Discurso (ADD), contemplando formulações em que o conhecimento é concebido de forma viva, produzido e recebido em contextos históricos e culturais específicos.

A ADD tem como unidade de análise o enunciado, aqui entendido não como frase, por ser utilizado por sujeitos na interação, que é a base das relações dialógicas, entendendo que:

As relações dialógicas são possíveis não apenas entre enunciações integrais (relativamente), mas o enfoque dialógico é possível a qualquer parte significante do enunciado [...], se ouvimos nela a voz do outro. Por isso, as relações dialógicas podem penetrar no âmago do enunciado [...], por outro lado, as relações dialógicas são possíveis entre os estilos de linguagem [...]. Por último, as relações dialógicas são possíveis também com a própria enunciação como um todo [...] (BAKHTIN, 2008, [1929], p. 210-211).

É fundamental ter em mente que a ADD possui como objeto de estudo o discurso e não unicamente a língua. $O$ discurso utiliza-se da língua para construir textos. Desse modo, ele só pode ser entendido quando houver a identificação de para quem foi escrito, em que lugar, em qual situação sócio-política e a quem se destinam, entre outros critérios.

Os procedimentos de organização das categorias de análise foram as seguintes: a) leitura dos manuais, identificando as categorias de análise; b) escolha de trechos representativos dos discursos identificados; c) escrita do texto conforme as categorias, realizando a comparação de posicionamentos entre os manuais; e d) um quadro que sumariza o resultado da análise. 
http://dx.doi.org/10.5902/1984686X38402

\section{Análise dos materiais didático-pedagógicos}

\section{Concepções de linguagem}

A concepção de linguagem da "Proposta curricular para deficientes auditivos" está muito ligada à divulgação, por parte dos pesquisadores das novas correntes linguísticas que estavam em larga expansão no Brasil nos anos de 1960, especificamente o estruturalismo com os estudos do Curso de Linguística Geral, de Ferdinand Saussure, e com a Gramática Gerativa Transformacional, de Noan Chomsky, que estavam sendo discutidas nas universidades brasileiras.

A tese que fundamenta o manual "Proposta curricular para deficientes auditivos", conforme a classificação das tendências do pensamento filosófico-linguístico formulada por Volóchinov (2017), é do objetivismo abstrato, centrada na visão de linguagem como sistema linguístico, nos termos que:

Um dos postulados iniciais da linguística moderna é o que distingue a linguagem da fala, sendo a linguagem definida como um sistema de signos, incluindo as regras que governam as maneiras pelas quais elas podem ser usadas, e a fala como o uso particular que o indivíduo faz deste sistema na sua comunicação oral (BRASIL, 1979, VII, p. 17).

Uma informação relevante é que o nome da disciplina "Língua Portuguesa" foi modificado para “Comunicação e Expressão” pela Lei no 5.692, de 11 de agosto de 1971. Segundo A LDB de 1971:

Art. $4^{\circ}$ Os currículos do ensino de $1^{\circ}$ e $2^{\circ}$ graus terão um núcleo comum, obrigatório em âmbito nacional, e uma parte diversificada para atender, conforme as necessidades e possibilidades concretas, às peculiaridades locais, aos planos dos estabelecimentos e às diferenças individuais dos alunos.

[...]

$\S 2^{\circ}$ No ensino de $1^{\circ}$ e $2^{\circ}$ graus dar-se-á especial relevo ao estudo da língua nacional, como instrumento de comunicação e como expressão da cultura brasileira (BRASIL, 1971, p. 2).

Os fatores principais que acarretaram a mudança da disciplina foram os próprios contextos do regime de ditadura estabelecido no país, a qual, no que diz respeito à educação, precisava sufocar as teorias críticas que supostamente estavam nas salas de aula e passavam a ser rotuladas de comunistas, sendo que a mentalidade conservadora deveria incutir que o objetivo do ensino era preparar para o mercado de trabalho e para isso bastaria o aluno aprender a se comunicar e se expressar, o que supostamente 0 estaria instrumentalizando para atuar no mercado ou obter um emprego. 
http://dx.doi.org/10.5902/1984686X38402

A alteração da denominação para "Comunicação e Expressão" ocorreu em função da ascensão da teoria da Comunicação, que:

\begin{abstract}
[...] surge nos anos de 1970, como quadro referencial para a análise da língua, transposta da área dos meios eletrônicos de comunicação, a teoria da comunicação. A concepção da língua como sistema, prevalente até então no ensino da gramática, e a concepção da língua como expressão estética prevalente inicialmente no ensino da retórica e da poética e, posteriormente, no estudo de textos, são substituídas pela concepção da língua como comunicação. Os objetivos passam a ser pragmáticos e utilitários: trata-se de desenvolver e aperfeiçoar os comportamentos do aluno como emissor e recebedor de mensagens, através da utilização e compreensão de códigos diversos - verbais e não-verbais. Ou seja, já não se trata mais de estudo sobre a língua ou de estudo na língua, mas de desenvolvimento do uso da língua (SOARES, 2002, p. 169).
\end{abstract}

Pietri (2010), outro pesquisador da história da disciplinarização da Língua Portuguesa, esclarece que "Comunicação e Expressão" inclui as disciplinas Língua Portuguesa, Educação Artística e Educação Física, e complementa o objetivo do ensino de Língua Portuguesa, o qual parece induzir para o estudo do uso da língua. A alteração da denominação da disciplina pode:

\begin{abstract}
ter como base, para sua estruturação interna, a teoria da comunicação -, minimizando-se, em relação aos conteúdos, os conhecimentos próprios ao ensino gramatical tradicional (o que caracterizaria, inclusive, um hiato em relação ao que anteriormente constituía essa disciplina); e de ter como objetivo formar cidadãos instrumentalizados para o mercado de trabalho, aptos para as exigências que o desenvolvimento econômico apresentaria, o que teria conferido caráter pragmático à disciplina (PIETRI, 2010, p. 71).
\end{abstract}

Percebemos no manual a preocupação em realizar um diagnóstico médicopatológico, entre os quais está o da caracterização dos níveis de comunicação do surdo. O destaque aqui está no uso da fonética para identificação dos níveis, que vai do 1 até o 8. O nível 1, para se ter uma ideia corresponde a recepção de vogais como o /a/; /e/ e /i/; as consoantes oclusivas /p/ou/b/ ou /m/ até chegar no nível 8 que corresponde a recepção e emissão de todos os fonema da língua portuguesa.

No que diz respeito ao uso da linguagem ou da gramática, a proposta curricular para deficientes auditivos faz opção pela gramática.

Curioso é que as formulações iniciais das concepções de língua referem-se à gramática gerativo-transformacional para subsidiar as formulações a respeito de aquisição da linguagem. Nos termos do manual: 
http://dx.doi.org/10.5902/1984686X38402

Todo o estudo da aquisição de linguagem pela criança, como foi descrita, fundamenta-se, teoricamente, em princípios da gramática gerativa transformacional. De acordo com os postulados deste modelo linguístico, a criança tem uma capacidade para adquirir linguagem, bastando que ela seja exposta a padrões linguísticos para induzir as regras da gramática de sua língua, de onde deduzimos que o fator ambiental é de fundamental importância para a aquisição de linguagem. Estudos mostram que crianças criadas sem estimulação ambiental desenvolvem linguagem de forma falha ou com atraso. (BRASIL, 1979, p. 16-17).

Nossa curiosidade está em citar esse tipo de gramática e, logo em seguida, apresentar para a classificação dos fonemas da língua, utilizando os pressupostos da descrição saussuriana da língua e não os diagramas arbóreos do gerativismo para tratar da sintaxe. Outro fato é defender que "[...] o trabalho com o deficiente auditivo deve ter como objetivo a aquisição da linguagem e não simplesmente a produção da fala" (BRASIL, 1979, p. 17), uma vez que para o gerativismo a linguagem é inata e não adquirida.

O manual trabalha as teorias atuais para a época como a fonética estruturalista e chega a citar o gerativismo, mas acaba na classificação da proposta curricular trabalhando a gramática normativa, ou seja, mantendo o ensino das classes gramaticais: "substantivos, adjetivos, artigo, pronome, numeral, advérbio e verbo, preposição, conjunção, interjeição e pronome relativo" (BRASIL, 1979, p. 40).

O ponto central da proposta dos conteúdos de ensino são os fonemas e as classes gramaticais. Os textos, jogos, passeios, ditados orais e de ritmo, ordens e instruções, contações de histórias etc. não são considerados como estratégias de ensino.

O manual "Ensino de Língua Portuguesa para Surdos: caminhos para prática pedagógica" trata na unidade III, do volume 1 especificamente, das teorias no ensino da língua. O título da unidade III é "Aplicações da teoria linguística ao ensino de línguas - Da abordagem áudio-lingual à interacionista: em direção à comunicação" (BRASIL, 2002, p. 95-6). Essa unidade traz-se as principais abordagens e métodos utilizados no ensino de segunda língua/língua estrangeira, o percurso histórico, a aplicação e a situação dos surdos no que concerne ao texto escrito e ao diálogo visual, orientando como esses fatores podem oportunizar contextos de aprendizagem para esse indivíduo. As abordagens trabalhadas foram a estruturalista, a funcionalista e a interacionista, que serão apresentadas brevemente, conforme o manual. 
http://dx.doi.org/10.5902/1984686X38402

$\mathrm{Na}$ introdução da unidade é explicado sobre a utilização do sequenciamento cronológico das abordagens, uma vez que "pretende-se mostrar como a trajetória do ensino de $\mathrm{L} 2$ foi se direcionando cada vez mais para conceitos centrais do ato de comunicação" (BRASIL, 2002, v. 1, p. 96). Posteriormente, são discutidos os níveis conceituais: abordagem, método e técnica. A abordagem e o método são, respectivamente:

\begin{abstract}
Abordagem: conjunto de suposições teóricas acerca da natureza da língua, da natureza da aprendizagem de uma língua, e da aplicabilidade de ambas no contexto pedagógico. A abordagem é axiomática; ela descreve a natureza do assunto a ser ensinado.

Método: conjunto de especificações gerais que visa à apresentação ordenada do material linguístico e que segue uma determinada abordagem. O método é procedural. Uma abordagem pode gerar inúmeros métodos (BRASIL, 2002, v.1, p. 97).
\end{abstract}

De acordo com os conceitos apresentados, entende-se que a abordagem compreende às concepções teóricas e ao método e, ao utilizar uma abordagem para proposta de um método, tem-se o desenvolvimento de concepção de língua.

Os organizadores do manual - Heloisa Maria Moreira Lima Salles, Enilde Faulstich, Orlene Lúcia Carvalho e Ana Adelina Lopo Ramos - apresentam a relação entre abordagens e métodos, explicando que "adotar uma abordagem como suporte para a elaboração de um método implica estabelecer uma concepção de língua, que servirá de base para se definir como ela deverá ser ensinada e aprendida" e ao considerar as correntes linguísticas, são destacadas as abordagens: "a estruturalista (anos 50 e 60), a funcionalista (anos 70) e a interacionista (anos 80 até os dias de hoje)" (BRASIL, 2002, v.1, p. 98). Para cada uma das três abordagens são apresentadas concepção de língua, natureza da aprendizagem e exemplo de aplicação.

$\mathrm{Na}$ abordagem estruturalista a concepção adotada de língua é que

A. Concepção de língua: a língua é concebida como um sistema de elementos relacionados estruturalmente, usados para a codificação e decodificação do significado.

B. Natureza da aprendizagem: o objetivo da aprendizagem de uma língua é o domínio dos elementos desse sistema, definidos em termos de unidades fonológicas, unidades gramaticais (sintagmas, sentenças), operações gramaticais (adicionar, alternar, juntar, etc.) e itens lexicais (BRASIL, 2002, v.1, p. 99). 
http://dx.doi.org/10.5902/1984686X38402

Nessa concepção, os autores ressaltam o ensino dos componentes de uma língua como a Língua Portuguesa - com unidades como o fonema, o morfema e o sintagma - e apresentam o conceito de língua em cada abordagem.

O estruturalismo linguístico enfatiza as estruturas de uma língua não se preocupando com aspectos sociais e históricos da língua: quem fala, com quem fala, onde fala, quando fala, com que objetivo e outras circunstâncias envolvidas. Os procedimentos nessa perspectiva estão apoiados na ideia da memorização, na resolução de exercícios mecânicos, na memorização de fórmulas e de conceitos, que são o foco do ensino. A atenção é voltada para a forma da expressão e para a forma do conteúdo.

A abordagem funcionalista considera que:

\begin{abstract}
A. Concepção de língua: a língua é concebida como um meio para a expressão de significados funcionais. [...].

B. Natureza da aprendizagem: enfatizam-se as dimensões semântica e comunicativa, o que leva a uma especificação e organização do conteúdo a ser ensinado com base em categorias de significados e funções, em vez de elementos estruturais e gramaticais (BRASIL, 2002, v.1, p. 100).
\end{abstract}

O que significa que a língua é concebida como um instrumento não-autônomo.

Esses pressupostos admitem que essa concepção de língua considere também as regras pragmáticas e sociais da língua, além dos princípios organizacionais. Esse modelo teórico apresenta dois aspectos "o aspecto funcional desse programa reside em sua organização com base em funções comunicativas, tais como identificar, relatar, negar, recusar um convite, pedir permissão, desculpar-se, etc. Em relação ao aspecto nocional, ele opera com dois tipos de noções: as noções gerais e as específicas" (BRASIL, 2002, v.1 p. 100, ênfase dos autores do manual). Por meio desses aspectos são trabalhados conceitos abstratos e contextos.

Sob a ótica funcionalista, o método áudio-lingual é sugerido, como fazendo parte deste, uma vez que:

[...] reflete não somente os pressupostos teóricos do estruturalismo linguístico, com maior ênfase nas estruturas da língua, como também as ideias da psicologia behaviorista, que defende os modelos de condicionamento, reforço positivo e formação de hábito como base para a aprendizagem (BRASIL, 2004, p. 99).

Nesse método, a língua é tratada como um sistema formal e descontextualizado, focando o produto, resultado do ensino, ou seja, atingir uma pronúncia como a do falante nativo. 
Na terceira abordagem, a interacionista, os autores do manual pontuam a ocorrência de duas vertentes teóricas, que chamam de a Hipótese da Interação e a Teoria Sociocultural.

A primeira - a hipótese da interação - está fundada na negociação de significados entre os participantes, no decorrer de uma conversa. Se não ocorrer entendimento ou compreensão do que falam ocorrem pedidos de esclarecimentos, verificação da compreensão, confirmações ou reformulações dos enunciados.

A segunda - a teoria sociocultural - está centrada no apoio recebido pelo aprendiz no decorrer da interação. Baseia-se, segundo os autores, na concepção de Vygotsky de desenvolvimento das funções psicológicas superiores, que ocorre a colaboração entre um aprendiz e outro sujeito com mais experiência.

Em termos gerais, os autores do manual resumem estas vertentes em um quadro, que reproduzimos a seguir:

Quadro 1 - Contraste ente a Hipótese da Interação e a Teoria Sociocultural

\begin{tabular}{|l|l|}
\hline Hipótese da Interação & Teoria Sociocultural \\
\hline 1. Interação social & Interação social e particular \\
\hline $\begin{array}{l}\text { 2. Um tipo de interação: a negociação de } \\
\text { significado }\end{array}$ & $\begin{array}{l}\text { Interação como um todo, apesar de sugerir } \\
\text { formas específicas: conversas instrucionais, } \\
\text { interação como uma prática social }\end{array}$ \\
\hline $\begin{array}{l}\text { 3. Interação corno auxílio à aquisição; } \\
\text { satisfaz as necessidades de informação do } \\
\text { aprendiz }\end{array}$ & Interação modela e constrói o aprendizado \\
\hline $\begin{array}{l}\text { 4. Interação facilita, mas não é necessária } \\
\text { nem suficiente para a aprendizagem }\end{array}$ & $\begin{array}{l}\text { Lugar real do aprendizado, é vista como } \\
\text { fundamental e suficiente }\end{array}$ \\
\hline
\end{tabular}

Fonte: Brasil (2004, p. 106).

A concepção de ensino interacionista tem como base a ideia de interação entre organismo e meio, e essa inter-relação existente pode favorecer o processo de aprendizagem. Neste modelo, o aluno não é um ser passivo, ao contrário, assume um papel ativo dentro do processo de ensino e aprendizagem sendo responsável por sua aprendizagem.

No que tange a ideia de natureza da aprendizagem do modelo interacionista, os autores do manual esclarecem que: 
http://dx.doi.org/10.5902/1984686X38402

a ideia central nessa abordagem é a de que a aprendizagem se dá por meio do exercício comunicativo de interagir, por meio da construção do discurso. Como as teorias interacionistas concentram-se nos padrões de ação e de negociação encontrados em trocas conversacionais, o conteúdo do ensino pode ser especificado e organizado em termos de padrões de trocas e interações, ou pode permanecer sem especificações, a ser modelado pelas inclinações dos aprendizes como agentes construtores da interação. Não se trata, portanto, de considerar as funções comunicativas da língua como possibilidades que 0 aluno poderá exercitar em futuras situações, provavelmente fora da sala de aula, mas de fazer com que o aluno vivencie a interação em sala, transformando esse ambiente em realidade discursiva e aproximando-o, dentro do possível, à realidade 'lá fora' (BRASIL, 2004, p. 103).

Portanto, torna-se evidente que $\mathrm{o}$ ato de interagir é fundamental para o sucesso da abordagem interacionista, assim os métodos de ensino que utilizam a concepção como base passam a desenvolver a interação como situação dinamizadora, tornando a sala de aula um lugar interativo onde acontecem diálogos reais, espontâneos ou simulados.

Tal fato pode ser justificado pela ação da vivência em sala de aula, com uso de diálogos que dramatizam a vida cotidiana. Quando utilizada a abordagem interacionista, é possível desenvolver um ambiente oportuno para aprendizagem, defendem os autores.

No volume 2 do manual, os métodos apresentados são associados aos temas do ensino de língua, e estes são organizados em duas esferas: temas de teoria do texto e temas de teoria gramatical. Esses posicionamentos e propostas de conteúdo de ensino parecem ir em direção contrária à abordagem interacionista, uma vez que se centra no ensino de estruturas, por meio de unidades desprovidas de historicidade.

Posteriormente a apresentação das sugestões, o manual enfatiza que cada texto tem suas particularidades e aplicar todas as sugestões é inviável. Quanto aos procedimentos metodológicos, sugeridos nesses aspectos macroestruturais e microestruturais, observamos uma aproximação com a linguística textual.

É possível identificar no manual "Saberes e práticas da inclusão" as três concepções de linguagens que entram em conflito entre si. Essa identificação é possível em decorrência da organização do texto e das autorias que se apresentam: o manual é organizado em sete encontros, sendo que os dois primeiros - Gomes em "A audição e a Surdez" e Noronha-Souza em "Reabilitação oral e Dispositivos de Amplificação Sonora" direcionam para o estudo da constituição, do funcionamento do sistema auditivo humano e do funcionamento dos dispositivos de amplificação sonora. 
http://dx.doi.org/10.5902/1984686X38402

Nesta ocasião, a língua é vista como som que se propaga no ar e é decodificada pelo aparelho fonador. A fala é "o resultado do movimento dos órgãos fono-articulatórios, que por sua vez provoca movimentação das partículas de ar, produzindo então o som" (BRASIL, 2003, p. 13). Identificamos a concepção de instrumento de comunicação, embora o aspecto central ainda não seja a comunicação, apenas a recepção auditiva de "sons" pelo aparelho fonador.

Outra concepção identificada é representada pelo texto "A linguagem e a surdez" (BRASIL, 1997) ${ }^{3}$, em que são defendidos os pressupostos inatistas da linguagem, em que o ser humano nasce com uma predisposição para falar o idioma do país em que nasce, traz uma gramática universal. O gerativismo Chomskyano "permite ao homem estruturar seu pensamento, traduzir o que sente, registrar o que conhece e comunicar-se com outros homens. Ela marca o ingresso do homem na cultura, construindo-o como sujeito capaz de produzir transformações nunca antes imaginadas" (BRASIL, 2003, p. 32).

Noan Chomsky é o representante do gerativismo cartesiano, uma vez que reduz o "funcionamento da Língua a um conjunto de regras formais" (COLOMBAT; FOURNIER; PUECH, 2017, p. 28), apresentando como principais traços a criatividade e a articulação entre estrutura profunda e de superfície. Na avaliação, é de expressão do pensamento. A justificativa é a seguinte: "A exposição a um ambiente linguístico é necessária para ativar a estrutura latente e para que a pessoa possa sintetizar e recriar os mecanismos linguísticos" (BRASIL, 2003, p. 33).

No texto há a defesa de que é possível que ocorram dificuldades de aquisição da língua, com o fim de ativação das faculdades inatas. Há possibilidade das diferenças individuais, em que crianças ditas "normais" e um grande número de crianças "com necessidades especiais" tenham dificuldade em aprender uma língua.

No caso do surdo, é afirmado que se trata de um outro sistema, chamado de motor em oposição ao sensorial. Tal argumento estabelece certo estatuto de língua para a forma de expressão utilizada pelos surdos, daí o termo "língua de sinais". Nos marcos postos no manual: 
http://dx.doi.org/10.5902/1984686X38402

Já está comprovado cientificamente que o ser humano possui dois sistemas para a produção e reconhecimento da linguagem: o sistema sensorial, que faz uso da anatomia visual/auditiva e vocal (línguas orais) e o sistema motor, que faz uso da anatomia visual e da anatomia da mão e do braço (língua de sinais). Essa é considerada a língua natural dos surdos, emitida através de gestos e com estrutura sintática própria. $\mathrm{Na}$ aquisição da linguagem, as pessoas surdas utilizam o segundo sistema porque apresentam o primeiro sistema seriamente prejudicado (BRASIL, 2003, p. $34)$.

A terceira concepção de linguagem pode ser identificada no texto de Fernandes, quando esta defende a língua de sinais como experiência visual dos surdos e como produto da interação social dos sujeitos que a utilizam.

A defesa dessa autora dá certo estatuto linguístico para a língua de sinais:

As línguas de sinais devem ter o mesmo status das línguas orais, uma vez que se prestam às mesmas funções: podem expressar os pensamentos mais complexos, as ideias mais abstratas e as emoções mais profundas, sendo adequadas para transmitir informações e para ensinar. São tão completas quanto as línguas orais e estão sendo estudadas cientificamente em todo o mundo. Coexistem com as línguas orais, mas são independentes e possuem estrutura gramatical própria e complexa, com regras fonológicas, morfológicas, semânticas, sintáticas e pragmáticas (BRASIL, 2003, p. 76).

A língua de sinais é definida como um "produto da interação", que se realiza pelo visual, favorece a socialização e a aquisição de valores, normas sociais. Nos termos que:

Por ser uma língua viva, produto da interação de um grupo de pessoas que se identificam pela comunicação visual, a língua de sinais, oferecendo as possibilidades de constituição de significado, cumpre um papel fundamental no desenvolvimento linguístico, cognitivo e emocional dos alunos surdos, não podendo ser ignorada pelo professor em qualquer ato de interação com eles (BRASIL, 2003, p. 77).

No que diz respeito ao conceito de Língua - especificamente da Libras - o manual Abordagem bilíngue na escolarização de pessoas com surdez estabelece:

Libras, um sistema linguístico com características e status próprios (BRASIL, 2010, p. 8).

As línguas de sinais são línguas naturais e complexas que utilizam o canal visual-espacial, articulação das mãos, expressões faciais e do corpo, para estabelecer sua estrutura. Todas as línguas são independentes umas das outras e as línguas de sinais possuem estruturas gramaticais próprias, compostas de aspectos linguísticos: fonológico, morfológico, sintático e semântico -pragmático (BRASIL, 2010, p. 14).

No Brasil, a Libras, reconhecida pela Lei 10.436/2002, é entendida como a forma de comunicação e expressão em que o sistema linguístico de natureza visual-motora, com estrutura gramatical própria, constitui um sistema linguístico de transmissão de ideias e fatos, oriundos de comunidades de pessoas surdas do Brasil (BRASIL, 2010, p. 15). 
http://dx.doi.org/10.5902/1984686X38402

Em função dessa relação de língua enquanto sistema, centrado na estrutura gramatical e no fato de servir para a transmissão de ideias e fatos, este manual aproximase da concepção de instrumento de comunicação.

\title{
Políticas linguísticas
}

O manual "Proposta curricular para deficientes auditivos" apresenta três métodos - o gestual, os orais e os orais-gestuais (misto) - e acaba por defender o método oral como:

\begin{abstract}
A estreita relação existente entre retardo de linguagem e estes aspectos prejudicados leva-nos a adotar uma linha onde todo o esforço deve se voltar para um desenvolvimento cada vez maior da função simbólico-verbal. Esta premissa não invalida o trabalho a ser feito com conexão de fala, mas subordina esta última a um enfoque mais amplo, ao desenvolvimento de um instrumento que possibilite o indivíduo a receber informações da sociedade que 0 rodeia, bem como a exprimir seus pensamentos e sentimentos de forma a poder ser compreendido pela população em geral. Além disso, considerando não existir, praticamente, deficiência auditiva total, a sua educação deve visar uma integração das diversas percepções, cujos canais sensoriais estejam íntegros, com a percepção auditiva prejudicada, através de meios e técnicas que favoreçam esta integração (BRASIL, 1979, p. 24).
\end{abstract}

Os argumentos para a escolha do método oralista são a referência à lesão auditiva que é chamada de "retardo da linguagem", a necessidade de ocorrer a função simbólicaverbal, o qual implica no recebimento de informações do mundo e poder ser entendido pela sociedade, e por último, o argumento de que não existe uma deficiência auditiva total, sempre há alguns "restos auditivos" que podem ser aproveitados para o ensino do oral, e o oral se dará por meio de fonemas da Língua Portuguesa.

Antes de apresentar a proposta a ser ensinada em cada série do ensino fundamental, os autores fazem a opção pelo método e pela abordagem a ser utilizada: "a proposição do método oralista, através da abordagem multissensorial, onde o deficiente auditivo receberá, através da leitura orofacial e dos restos auditivos, a mensagem oral e escrita, compreendendo-a e interpretando-a" (BRASIL, 1979, p. 39).

Os autores fazem uma classificação das teorias chegando a citar o oralismo, a comunicação total e o método gestual, incluindo a linguagem gestual ou mímica ou a linguagem de sinais. Notamos que o bilinguismo ainda não existia na década de setenta do século vinte, só vinda a aparecer nos anos de 1980, com a experiência na Suécia. 
Chega a definir o que seria a linguagem gestual:

A linguagem mímica ou linguagem dos gestos é um instrumento mediante 0 qual os surdos-mudos suprem espontaneamente a privação do ouvido e da palavra, a fim de poderem comunicar-se entre si e com os outros.

Todos os deficientes auditivos possuem esse tipo de linguagem sem que Ihes tenha sido ensinado. A linguagem mímica é natural. Muitos dos gestos são comuns às diferentes linguagens mímicas. A semelhança é tão grande que existem deficientes auditivos de diferentes nacionalidades que se entendem melhor que os ouvintes estrangeiros" (BRASIL, 1979, p. 25).

Podemos deduzir que pelos argumentos de que são facilmente aprendidos, sem precisar de ensino, por serem "universais", não precisariam ser valorizados e ter um ensino formal de gestos e de mímicas.

Em função de defender o ensino unicamente por meio da oralidade, conclui-se que a política pública defendida neste manual é monolíngue.

O manual "Ensino de Língua Portuguesa para Surdos: caminhos para prática pedagógica" defende explicitamente a perspectiva do bilinguismo no ensino de surdos, embora não caracterize a mesma.

Os autores entendem que a proposta de educação bilíngue é

Uma proposta de ensino que preconiza o acesso a duas línguas no contexto escolar, considerando a língua de sinais como língua natural e partindo desse pressuposto para o ensino da língua escrita. A proposta bilíngue busca resgatar o direito da pessoa surda de ser ensinada em sua língua, a língua de sinais, levando em consideração os aspectos sociais e culturais em que está inserida" (BRASIL, 2002, v. 1, p. 57).

$\mathrm{Na}$ avaliação desta pesquisa, os autores avançam bastante ao enumerar fatores que interferem na definição de uma proposta pedagógica, dentre os quais o grau de surdez, o fato de ter nascido surdo ou ter ficado surdo, em uma fase após a aquisição da oralidade, além de outros fatores sociais como a classe social e a possibilidade de ter acesso a algum tratamento ou a políticas públicas de saúde e de educação. Verificamos que:

Na prática, porém, a situação é ainda mais complexa: [...] a surdez é uma realidade heterogênea e multifacetada e cada sujeito surdo é único, pois sua identidade se constituirá a depender das experiências socioculturais que compartilhou ao longo de sua vida.' São decisivos para a diversidade e complexidade da realidade do surdo fatores como o grau da surdez (profunda, severa, moderada, leve), a origem da surdez (congênita ou adquirida - e, no último caso, a idade da perda da audição), o fato de os pais serem ou não surdos, a sensibilidade dos pais e educadores para as necessidades de comunicação do surdo, em particular a capacidade dos mesmos na utilização da língua de sinais, as políticas públicas de educação e saúde (BRASIL, 2002, v. 1, p. 78). 
http://dx.doi.org/10.5902/1984686X38402

Essa proposta considera para os indivíduos surdos a Língua de Sinais como primeira língua e como segunda língua a Língua Portuguesa. Essa concepção vislumbra o contato das crianças surdas com pessoas fluentes na língua - Libras, uma vez que o desenvolvimento da língua materna - a primeira língua - faz-se imprescindível para o desenvolvimento deste indivíduo como pessoa.

A política educacional em torno do ensino e da aprendizagem das línguas é apresentado no tópico das "Expectativas de Aprendizagem" posta no material didático de "Saberes e Práticas Inclusivas" (BRASIL, 2003) como podemos observar: "Dissertar criticamente sobre as diferentes concepções e paradigmas que atualmente coexistem no trato da aprendizagem das línguas pelo surdo e das formas de comunicação (monolinguismo e bilinguismo). (BRASIL, 2003, p. 7)".

No texto de Sueli Fernandes, "Conhecendo a surdez", há a defesa explicita da educação bilíngue: "Os surdos têm direito a uma educação bilíngue, que priorize a língua de sinais como sua língua natural e primeira língua, bem como o aprendizado da língua portuguesa, como segunda língua" (BRASIL, 2003, p. 71).

O manual "Abordagem bilíngue na escolarização de pessoas com surdez" desde o seu título assume a abordagem bilíngue na educação de surdos, justificando que "a abordagem educacional por meio do bilinguismo visa capacitar a pessoa com surdez para a utilização de duas línguas no cotidiano escolar e na vida social, quais sejam: a língua de sinais e a língua da comunidade ouvinte" (BRASIL, 2010, p. 7).

Propõe um ensino multilíngue, mais adiante irá propor que o ensino da Libras e da Língua Portuguesa se dê de três modos: AEE em Libras, AEE de Libras, AEE de Língua Portuguesa. Todos esses modos devem ocorrer em horário oposto ao da sala de aula, por professores do Atendimento Educacional Especializado. Portanto, apesar de propor um ensino bilíngue - de Libras e de Língua Portuguesa - este fica restrito à sala de recursos multifuncionais do AEE. A sumarização do quadro 2 permite compreender os seguintes resultados: 
http://dx.doi.org/10.5902/1984686X38402

Quadro 2 - Sumarização das concepções de linguagem e das políticas linguísticas dos manuais

\begin{tabular}{|l|l|l|l|l|}
\hline & BRASIL (1979) & BRASIL (2002) & BRASIL (2003) & BRASIL (2010) \\
\hline Conceito & $\begin{array}{l}\text { Linguagem como } \\
\text { sistema linguístico } \\
\text { (IC). }\end{array}$ & $\begin{array}{l}\text { Língua como } \\
\text { forma de interação } \\
\text { (LI) }\end{array}$ & $\begin{array}{l}\text { Sons da língua } \\
\text { (IC); Capacidade } \\
\text { inata (EP); } \\
\text { Interação social } \\
\text { (LI). }\end{array}$ & $\begin{array}{l}\text { Língua como } \\
\text { sistema } \\
\text { linguístico (IC) }\end{array}$ \\
\hline $\begin{array}{l}\text { Política } \\
\text { publica }\end{array}$ & $\begin{array}{l}\text { Método oralista. } \\
\text { Política } \\
\text { monolíngue. }\end{array}$ & $\begin{array}{l}\text { Defende a } \\
\text { educação } \\
\text { bilíngue. } \\
\text { Multilíngue (LI). }\end{array}$ & $\begin{array}{l}\text { Defende a } \\
\text { educação } \\
\text { bilingue. (LI). }\end{array}$ & $\begin{array}{l}\text { Política } \\
\text { multilíngue no } \\
\text { AEE (LI). }\end{array}$ \\
\hline
\end{tabular}

Legenda: Expressão do Pensamento (EP); Instrumento de Comunicação (IC); Lugar de Interação (LI) Fonte: Elaboração dos autores (2019).

Notamos um avanço na política linguística com relação à educação bilíngue assumida, entre 1990 e 2010, como proposta do MEC nos três materiais com relação ao uso de Língua Portuguesa e Libras em que a leitura e a escrita de textos em português como L2 e a Libras como língua de interação, sob o Atendimento Educacional Especializado-AEE nas salas multifuncionais no ambiente escolar inclusivo junto ao trabalho dos profissionais das salas comuns em que tem aluno(a)s surdo(a)s.

Este posicionamento vem como resposta à abordagem monolíngue, defendida no primeiro manual, durante a década de 1970 e 1980. Esse primeiro discurso de ensino monolíngue com base no método oralista para o preparo da fala e da escrita em Língua Portuguesa.

Os programas de governos e seus respectivos materiais determinaram a política educacional, consequentemente a política linguística pensada como proposta oficial de ensino de Língua Portuguesa na educação de surdos durante 40 anos pautada, nas duas primeiras décadas (entre 1970 e 1980) uma proposta de ensino e sujeito monolíngue com base apenas no método oral: impostação da fala e do treino da escrita; e, nas duas décadas seguintes (entre 1990 e 2010) uma perspectiva de trabalho de ensino e sujeito bilíngue dentro do espaço escolar numa perspectiva de educação bilíngue em que a leitura e a escrita do texto em Português seja possível com a interação, entre os sujeitos, em Libras. 
http://dx.doi.org/10.5902/1984686X38402

\section{Considerações finais}

O Governo Federal, representado pelo MEC, assumiu diferentes posicionamentos com relação à política linguística postos nos materiais pedagógicos, os quais podem ser marcados em dois grandes momentos: no primeiro momento, com base no ensino monolíngue, ocorrido entre 1979 e 2000, pautado ora na fala e na escrita da Língua Portuguesa ora por meio de sinais e frases da gramática da Língua Brasileira de Sinais (Libras); e, no segundo momento, já em uma perspectiva bilíngue escolar inclusiva, entre 2002 e 2010, focado na leitura e na escrita de textos em português como L2 e em Libras como língua de interação (L1), sob a égide do Atendimento Educacional Especializado (AEE) na Sala de Recursos Multifuncionais da rede regular de ensino.

Esses diferentes posicionamentos com relação à política linguística podem ser notados a cada época: entre 1970 e 1980, quando predominou o ensino de língua baseado na perspectiva monolíngue, em que a fala e a escrita foram realizadas somente em português por meio de treinos de fonemas e apreensão de palavras isoladas; e, entre 1990 e 2000, o ensino quando predominou a estimulação das palavras em Língua Portuguesa falada e escrita e por meio de sinais, frases e pequenos diálogos da gramática de Língua Brasileira de Sinais (Libras).

Entre 2002 e 2006, o ensino de língua deu-se na perspectiva bilíngue nas classes, a leitura e a escrita de textos em português como L2 e a Libras como língua de interação, e, entre 2007 e 2010, com base na educação bilíngue na perspectiva escolar inclusiva, a Língua Portuguesa escrita é correlacionada à Libras sob o Atendimento Educacional Especializado (AEE) da Sala de Recursos Multifuncionais.

Os resultados desta pesquisa contribuem aos estudos da educação especial e aos estudos de linguística aplicada no que se refere aos estudos da linguagem na perspectiva dialógica da linguagem de Bakhtin e o Círculo. A contribuição emerge a medida que este estudo responde sobre qual concepção de língua na educação de surdos foi prioritária como projeto de formação de professores em cada governo federal pelos discursos assumidos do MEC nos quatro (4) materiais didático-pedagógicos analisados, entre os anos de 1979 e 2010.

O MEC apresentou três projetos oficiais de política linguística para orientar os professores no campo da educação de surdos no Brasil, consolidando uma política de Estado descontinua quando assume duas propostas de ensino, uma monolíngue que 
http://dx.doi.org/10.5902/1984686X38402

desconsidera justamente as peculiaridades da língua de sinais dos sujeitos surdos, entre 1979 e 1995, a outra bilíngue que considera o sujeito bilíngue na perspectiva da educação inclusiva em que o ensino da língua portuguesa escrita seja uma possibilidade de interação discursiva entre os sujeitos, que usam Libras, no único espaço bilíngue na escolar - o AEE.

\section{Referências}

BAKHTIN, Mikhail. Problemas da poética de Dostoiévski. Tradução do russo por Paulo Bezerra. 4. ed. rev. Rio de Janeiro: Forense Universitária, 2008.

BAKHTIN, Mikhail. Os gêneros do discurso. In: BAKHTIN, Mikhail. Os Gêneros do discurso. Organização, tradução, posfácio e notas Paulo Bezerra. Notas da edição russa Serguei Botcharov. São Paulo: Ed. 34, 2016. p. 11-69.

BRAIT, B. Análise e teoria do discurso. In: In: BRAIT, B. (Org.). Bakhtin: Outros conceitos-chave. São Paulo: Contexto, 2006. p. 9-31.

BRASIL. Lei no 5.692, de 11 de agosto de 1971. Fixa Diretrizes e Bases para o ensino de $1^{\circ}$ e $2^{\circ}$ graus, e dá outras providências. Disponível em:

http://www.planalto.gov.br/ccivil_03/leis/L5692.htm. Acesso em 28 fev. 2019.

BRASIL. Proposta curricular para deficientes auditivos. Elaborada pela divisão de educação e reabilitação dos distúrbios da comunicação - convênio CENESP-PREMEN. Brasília, MEC/Departamento de documentação e divulgação, 1979.

BRASIL, Secretaria de Educação Especial. A educação dos surdos. Organizado por Giuseppe Rinaldi et al. Brasília: MEC/SEESP. 1997. V. I e II.

BRASIL. Lei no 10.436, de 24 de abril de 2002. Dispõe sobre a Língua Brasileira de Sinais - Libras e dá outras providências. Disponível em http://www.planalto.gov.br/ccivil_03/leis/2002/l10436.htm. Acesso em 05 jun. 2017.

BRASIL. Saberes e práticas da inclusão: desenvolvendo competências para o atendimento às necessidades educacionais especiais de alunos surdos. Coordenação geral SEESP/MEC. Organização: Maria Salete Fábio Aranha. Brasília: MEC, Secretaria de Educação Especial, 2003.

BRASIL. Ensino de língua portuguesa para surdos: caminhos para a prática pedagógica / Brasília: MEC, SEESP, [2002] 2004. 2 v.

BRASIL. A educação especial na perspectiva da inclusão escola: a abordagem bilíngue na escolarização de pessoas com surdez. Brasília: Ministério da Educação, Secretaria de Educação Especial; Fortaleza: Universidade Federal de Ceará, 2010; 
http://dx.doi.org/10.5902/1984686X38402

COLOMBAT, Bernard; FOURNIER, Jean-Marie.; PUECH, Christian. Uma história das ideias linguísticas. Tradução: Jacqueline Léon e Marli Quadros Leite. São Paulo: Editora contexto, 2017.

PIETRI, Émerson de. Sobre a constituição da disciplina curricular de língua portuguesa. In: Revista Brasileira de Educação v. 15 n. 43 jan./abr. 2010. Disponivel em: http://www.scielo.br/pdf/rbedu/v15n43/a05v15n43.pdf. Acesso em 28 de fev. 2019.

VOLÓCHINOV, Valentin Nikolaevich. Marxismo e filosofia da linguagem: Problemas fundamentais do método sociológico na ciência da linguagem Tradução, notas e glossário de Sheila Grillo e Ekaterina Vólkova Américo. Ensaio introdutório de Sheila Grillo. São Paulo: Editora 34, 2017.

SAUSSURE, Ferdinad. Curso de linguística geral. Organizado por Charles Bally e Albert Sechehaye. 14ํㅜ ed., São Paulo: Editora Cultrix, 1988.

SOARES, Magda Becker. Português na escola - História de uma disciplina curricular. In: BAGNO, Marcos. (Org.). Linguística da norma. São Paulo: Loyola, 2002, p. 155-177.

\section{Notas}

${ }^{1}$ Defendemos a formulação de que FHC fora um governo neoliberal por realizar inúmeras privatizações de setores produtivos, como os setores: mineração, energia, siderúrgico, petroquímico e telecomunicações, instituindo a terceirização nos órgãos estatais e favorecendo a 'liberalização' comercial e financeira.

2 "Atendimento Educacional Especializado" (2007) foi também uma publicação do "Programa de Educação Inclusiva: direito à diversidade" (2007) com a finalidade de formação para os professores das salas multifuncionais que atuam no ensino básico, em Atendimento Educacional Especializado-AEE. Este material não foi incluído neste artigo em função deste trazer discussões semelhantes com os do material "Abordagem bilíngue na escolarização de pessoas com surdez" (BRASIL, 2010) no que tange ao tema.

3 Texto utilizado no material Brasil (1997). A linguagem e a surdez. Educação Especial - A educação dos Surdos, Série Atualidades Pedagógicas 04, volume II, pp. 279 - 282. Brasília: MEC/SEESP.

\section{Correspondência}

José Anchieta de Oliveira Bentes - Universidade do Estado do Pará, Departamento de Educação Especializada, Trav. Djalma Dutra, s/n, Belém, Pará Brasil. CEP: 66113-200.

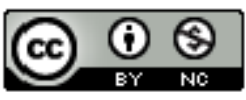

This work is licensed under a Creative Commons Attribution-NonCommercial 4.0 International (CC BY-NC 4.0) 